\title{
TOOLS DESCRIPTION FOR PRODUCT DEVELOPMENT PROCESS MANAGEMENT IN FOOD INDUSTRIES
}

\author{
De Greef $\mathbf{M}^{1}$, Arcusin $L^{2}$, Rossetti $\mathbf{G}^{3}$ \\ ${ }^{I}$ Doctoral scholar, Department of Industrial Engineering, Faculty of Chemical Engineering, Universidad Nacional del \\ Litoral, Santa Fe, Argentina \\ ${ }^{2}$ M. Sc, Department of Industrial Engineering, Faculty of Chemical Engineering, Universidad Nacional del Litoral, \\ Santa Fe, Argentina \\ ${ }^{3}$ Ph.D., Department of Industrial Engineering, Faculty of Chemical Engineering, Universidad Nacional del Litoral, \\ Santa Fe, Argentina
}

\begin{abstract}
This paper describes a set of tools developed by different authors that can be applied in the Pre-Development of Product Development Process in food industries. Product Development Process (PDP) is considered increasingly important to company competitiveness. The management of this activity is critical to detect customers needs and to offer products according to them, in order to optimize company resources and increase its profits. At food industry, this process is especially relevant due to the increase of products offered in the market and the reduction of their life cycles. Despite the existence of studies that seek to standardize the process of food product development, implementation of PDP models is incipient. Rozenfeld et al [1] propose a model that outlines the process in macrophases, phases and tools, that allows the implementation of new product development. This model was adapted by Penso [2] according to food industry characteristics. Both contributions have been taken as reference for this investigation.

Among the phases, it underscores Pre-Development macrophase, which involves planning portfolio organization in the context of its strategic plan. Its importance lies in the decisions made along the stage, that guide the process of further development and may determine the future business scenario. This indicates the need for appropriate tools in order to manage efficiently this macrophase. This paper describes different techniques and tools available in the literature related to PDP and structure them according to the activities developed in the Pre-Development macrophase in food industries.
\end{abstract}

Keywords: Product Development Process, Food, Pre-Development, Management Tools.

\section{INTRODUCTION}

The product development process (henceforth PDP) is a systematic task whose objective is to generate new products, either by modifying any existing or creating a completely new and original one [3].

For the food, this activity is crucial. The scenario where companies operate is characterized by high levels of competitiveness. Due to globalization, organizations must survive in a dynamic and often unpredictable market, with life cycles product increasingly shorter. For companies, competitive advantages are based on the optimization of cost, time and quality, especially in the PDP.

Product quality in the food sector is one of the priority criteria to analyze its performance in the consumer market, and is a variable that directly affects the design and production process thereof. Development time is an important factor, since it must follow changes in customer requirements, incorporates new technologies and attend the increasing competitiveness of the market in the introduction of innovative products. Finally, productivity of the development process must be efficient, which means that new product development involves searching the best performance of material, financial and human resources available on the company. One of the biggest challenges of the PDP is to manage the best combination of these three factors for an efficient process. Consequently, determining appropriate models and tools will help to consolidate PDP management.

In the literature there are several proposals to systematize activities of product development in PDP models, according on the area of knowledge of authors. However, differences between these proposals are more terminological than conceptual [4].

Rozenfeld et al [1] present the most recent PDP contribution outlining the process into three macrofases: (i) predevelopment, (ii) development and (iii) post-development. The model is structured and works as a reference to guide its application into companies.

However, despite the existence of studies that seek to standardize product development in the food industry, the implementation of PDP models in the sector is incipient, as it is described in a research by Rossetti et al [5]. 
A stage that attract increasing interest in recent years in the literature of the PDP, is the macrophase called PreDevelopment by Rozenfeld et al [1] and Penso [2], which includes strategic aspects of the product, linking the PDP with company strategic vision and its market share. It involves the development of a number of activities that precede decision making to develop a new product. The importance of this step lies on the impact of these decisions, as they determine the direction of the PDP and also the future competitive business scenario.

The aim of this paper is to analyze the tools developed by different authors on the PDP, in order to propose the most appropriate to be used on pre-development macrophase PDP in food industries.

\section{METHODOLOGY}

To achieve the objective of the present work, a qualitative methodology is applied.

In the first place, the research method used is literature search. We proceed to locate, identify and access documents for research information. The literature review is to analyze and synthesize current literature, resulting a document of the state of art of PDP in food industry.

Next, tools studied are selected in terms of their specific application in food companies, classified according to the two phases in the Pre-Development macrophase selected.

\section{REFERENCE MODELS}

This paper bases its analysis on the model proposed by Rozenfeld et al [1]. It contains a PDP Management Model which separates the process into three macrofases: (i) predevelopment, (ii) development and (iii) post-development. Each of these macrofases is split into phases, activities and tasks. While the model shows phases sequentially in the sublevels of activities and tasks, is normal that there is simultaneity.

The model was originated from the binding of methodologies, case studies, models, experiences and best practices identified by the author and the research team. His contribution is to conceive a management program in a global way, involving all activities since development, release and until removal of a new product. It is therefore known as the Unified Model PDP, because it brings together academic and professional perspectives into a unique theoretical model [5].

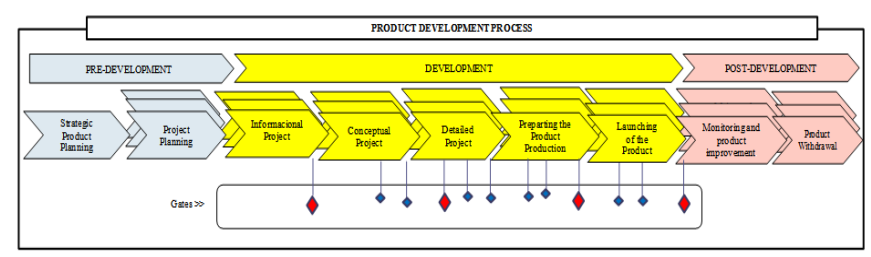

Fig -1: View of Rozenfeld et al. Model [1]
The model is structured and systematized in a practical way, and serves as a orientation to guide its application to several industries and situations. Each application of the Unified Model to a new industrial sector results in a Reference Model for the sector, that companies operating in it can use to improve their management systems of PDP.

Penso [2] focuses its research to make improvements in relation to previously published models, in order to adapt them to the food sector. It should be noted that, when preparing the reference model for the sector (2003), the Unified Model of PDP was in a publication process (2006). The author made a systematization of the PDP focused on the peculiarities of the development of food products. The proposed model (Penso, 2003) is structured in macrofases and phases similar to Rozenfeld et al [1], differing by adding some specific activities in the area of food in the macrophase Development.

\section{PRE-DEVELOPMENT MACROPHASE AND} ITS IMPORTANCE IN THE FOOD INDUSTRY

Pre-Development macrophase links the PDP with strategic vision of the company and its market share. This macrophase is composed by two phases:

1. The Product Strategic Planning phase, which objective is to integrate corporate strategic planning with company portfolio. In this phase, is provided a Plan containing the product portfolio of the company, from the Strategic Planning business. In fact, this Plan is a list that describes the product line of the company, the new product projects that can be designed to achieve the strategic goals, and the choose of one of them to be developed in the next phase. In general, leaders and managers of the company have influence in this phase.

2. Project Planning phase establishes the steps to be performed for the project development of a new product. That is, one of the projects planned in the new portfolio of products. This phase begins when the project is formally approved. Its result is the Project Plan, a document that will be used as a guide for the next macrophase (Product Development) and contains: project goals, product goals, description of activities, deadlines, budgets, responsible, resources, etc.

Food industry is generally characterized by saturated product markets, where there are leaders who consistently deliver innovations, leading to reduced life cycles of products. It is influenced by trends, lifestyles, and there is a large global investment in research and development of new products, in order to find opportunities from innovation in a traditional market [6].

Understand the importance of Pre-Development in food industry is essential for the survival and competitiveness of enterprises. This Macrophase involved many decision, such as the current portfolio of the company, the identification of opportunities, selecting new product concepts that present the greatest potential for success in the market, the 
determination of products to be discontinued, among other; decisions that are of vital importance because would guide further development, including setting the future competitive scenario of the company. Changes into projects as they approach completion are more expensive than if applied at startup. Good planning in these early stages can become a differentiating factor for organizations.

Properly manage PDP with right tools allows companies to stay in business and develop strategies based on higher value-added products for consumers that demand healthy, convenient and nutritious products.

\section{TOOLS PROPOSALS FOR PRE- DEVELOPMENT MACROPHASE}

Tools used in product development processes are a set of recommendations to stimulate ideas, analyze problems and structure process activities [2].

In Pre-development phase, these tools are essential to carry forward the different tasks proposed by the model and to arrive at concrete results, optimizing company resources.

Penso [2] systematized in his research several tools that can be used in the PDP of food products, some of them are generic in PDP (e.i., Brainstorming, Parametric Analysis, SWOT analysis) and some others are specific to the food industry (e.i., Sensory Analysis, Attributes Matrix, Life Cycle Map). The author presents these techniques in a common paragraph, without linking them to macrofases and phases proposed by the model.

This paper proposes a description of different tools according to the two phases that structure the macrophase of Pre-Development. After a literature review of the techniques used in the PDP, are selected the more appropriate to the mentioned stage.

According to Rozenfeld Model, are detailed below activities and tasks that include each of the phases of PreDevelopment (Strategic Product Planning and Project Planning), and tools that can be used to facilitate the achievement of them. It should be noted that these techniques and tools can be used together, and even some of them support others.

\subsection{Strategic Planning Product Phase:}

1. Define the purpose of the review of the Strategic Business Plan (SBP): Consists on analyzing the strategic business plan of the company, list issues to be discussed, assess the skills of management for strategic product planning, defining a review methodology of the SBP, set a deadline, and finally draft a document with the scope of this review.

2. Planning activities for SBP revision: It involves establishing calendars, discussions and decisions to make, planning the necessary physical resources at each meeting and prepare a communication plan that allows for this information to stakeholders.
3. Consolidating information on market and technology: This activity allows having information for decisionmaking: make available secondary data, detect the need to identify primary data and finally consolidate the obtained information.

4. Review of the SBP: Implies, with the obtained information, analyze internal and external factors of the organization: mission, technology trends, market segmentation, market positioning, and internal factors (e.i., goals, skills, resources). Finally, a document with the information obtained is prepared.

5. Analyze Portfolio of the Company: consists in a review of methodology for evaluating product portfolio, positioning and evaluating products performance, technologies used, and making a list of ideas for new products -called "projects"- and finally analyze these projects.

6. Changes to product portfolio: the procedure consist in identify products to be discontinued, projects to be left, and new projects to start. Documents for each of the new projects are prepared and the new product portfolio is consolidated.

7. To test the viability of product portfolio: it involves assessing the economic viability of project portfolio, assess the availability of resources, evaluate the skills to reach it and finally reach consensus on the final decision.

8. Decide the start of a product portfolio planning: Involves reviewing project documents and select one, also establishing a project manager and possible start dates, and finally approve and announce the decision.

To carry forward the activities of this stage has been found in literature several tools mentioned below:

SWOT Analysis (Strengths, Weaknesses, Opportunities and Threats) This technique is a simple and systematic way to verify the strategic position of the company, being the basis for the development of its strategic plan [3].

Strengths and weaknesses are determined by the current position of the company, and are related to internal factors of the organization. Opportunities and Threats are future anticipations, and are related to external factors of business environment.

The first step is to obtain relevant information from the company core businesses in which it operates, position, skills and finance, among others. This information is grouped and related to be analyzed and translated into strengths, weaknesses, opportunities and threats. This allows to identify the points that require changes and decide the best way to introduce them [2].

PEST (Political, Economic, Social and Technological) analysis The purpose of this tool is to determine the external conditions that could influence organizations. It is useful to extend the external variables of SWOT Analysis. From the four-factor it analyses the impact that changes in general economic and business environment lead on business operations, and consequently, the Product Development [2]. 
The analysis involving the PDP consider these factors: (i) Political: changes in laws and regulations, or policies that have impact on the market; (ii) Economic: macroeconomic issues such as growth rates, recession, fiscal policy, inflation; (iii) Social: demographic trends, environmental awareness, habits and lifestyles, and (iv) Technology: Advances in areas such as computer, communications, and science in general, which cause changes in some industries, new materials, processes and energy sources.

Market Research It involves compilation and analysis of market information, made in a systematically way [7].

There are some differences in scope and description of this technique according different authors. In general for this study are considered, according to Penso [2]:

(i) Information generated by the company. Involves considering the accumulated knowledge of the company in relation to its market, especially from the areas of higher contact with customers (marketing and technical assistance). Obtain this type of information is possible through meetings, discussions or formal interviews or 'wish lists' questionnaires.

(ii) Literature review. In specialized journals, reports and magazines published by companies related to the sector. Investigations are based on the unmet needs of consumers, but also must be focused on critical areas or uncertainty, on which depends the success of a new product.

(iii) Market Research. To organize market research, is critical to determinate methodologies, questions to be performed, and a representative sample of consumers (e.i., age, gender, educational background, socio-economic status). Measurement methods determine how the data will be processed and presented. The final step is to transform data into decisions (eg, take or reject a new product project).

One of the objectives of Market Research is identifying business opportunities. Lerma K. [3] assigns great importance to this concept, and specifically delves in Information Sources for detecting such opportunities: claims or complaints from consumers, study other goods or services satisfy the same needs elsewhere (trips), trade shows and exhibitions, publications (newspapers, magazines, catalogs), distributors of similar products, offices customer or offices repair.

Observation This tool is often used to investigate consumers behavior, providing important information for product design. It can be used naturally by observing behaviors as they occur in their usual environment, or based on a structured plan, to create situations where the behavior of the participants can be observed [7].

Consumer Panel Referring to the food industry, Penso [2] highlights this technique, which allows following the changes of consumers in relation to their perception of the company, brand or product, through its spontaneous opinion. The information obtained is used to generate ideas for new products or markets, improve existing products and evaluate the products of competitors.
Focus Group These are interviews with a sample of consumers to elaborate on specific topics. A moderator proposes some questions to obtain información about the way the group sees a brand, product, related images, slogans, existing concepts or symbols. It can also be used to study the initial perception of the concept or prototype of a new product.

Competitive Analysis This analysis aims to monitor competitors and their products, and seeks to identify factors of success and failure.

Following Penso [2], the first step is to collect information available about competitors (e.i., turnover, products developed, patents, production capacity). The nature of their business is then evaluated, and how that affects the performance of the company. To do this, the analysis of competitors Marketing Mix is used, studying each variable (product, price, promotion and place or distribution and communication).

Finally, conclusions of the analysis (strengths, weaknesses, opportunities and threats, and strategies) indicate the changes that the company should lead to increase their competitiveness.

Benchmarking Set some comparative frameworks, based on an analysis of best techniques existing on the market. Thus, attempts to determine the state of the art of processes used by the company, compared to other organizations (especially competitors) to identify and incorporate these practices in the company. The search should not be limited to similar organizations, but aims to find various kinds of solutions or innovations to continuously improve their processes and products [8].

Monitoring and Surveillance Technology Is the search for information related to external opportunities and threats in science and technology field [7]. Sources that may be useful for product development are: conferences, fairs, colleges developments, patent databases, databases of private and government agencies that collect existing technology, companies developing raw materials and equipment, among others [2].

Customers value chain Analysis Is the analysis of the chain of customers and product users (distribution, logistics, point of sales), focus on the aspects that adds value to each of them [2]. Thus, strategies for enhancing these aspects or valued activities are sought, to create advantage over competitors [7].

User Cooperation / Leaders suppliers Is to engage in idea generation lead users (those users who have knowledge of the product and its use) with the goal that ideas will be accepted in the market; as well as suppliers who have an advanced knowledge about product, distribution channels and technologies [7]. 
Warehouse ideas This tool seeks to build a storehouse of ideas that can be the useful for product development. It suggests to establish mechanisms to facilitate and encourage idea contribution by employees of the organization [7].

Analysis of product maturity (or Life Cycle) The life cycle analysis of products on the market intended to diagnose their performance depending on the stage they are: introduction, growth, maturity or decline. This tool is important for PDP strategic planning.

Scenario Analysis Scenario-based planning is projecting the future, describing possible scenarios: the best, the worst and most likely case, in terms of industry and market [7].

Delphi Method The purpose of this tool is to collect opinions of specialists through successive rounds of structured questionnaires. Another possibility is bringing together managers and directors of different departments to reach consensus on a decision to be taken [2].

Ideas selection based on Product Portfolio Is a dynamic process where the list of new products is reviewed and updated constantly, taking into account projects interrelationship in order to assign resources available in the best possible way [2].

Brainstorming These group sessions are managed to analyze a situation and provide solutions to a problem in a relatively short time. These meetings usually involved a small number of people (no more than ten or twelve), chosen based on their skills, knowledge of a particular area, or their creative abilities [2]. It consists of seven stages: Orientation, Preparation, Analysis, Ideas, Incubation, Synthesis and Evaluation [2]. This tool is used mainly in activities where creativity to generate ideas is required.

Question Checklist This tool seeks to present to product development team a number of questions about the product to be developed, in order to conceive possibilities otherwise are hardly considered. The questions are designed to lead the mind generate ideas. Some examples are: what other uses might have the desired product?, What are the latest technological trends, and which could be incorporated in the product? [3].

Simplex Method It consists of an outlined process for conducting creative thinking towards innovation in solving problems, taking as a starting point the identification of a specific problem, to respond to the challenges included in solutions intending [3].

Ansoff Matrix This tool has four possibilities to explore company business opportunities and is used primarily in the development of organizational strategy [2]. It takes into account two variables, markets and products, according to the presenting feature (traditional or new). In relation to the PDP, the tool is useful for locating the product to be developed in a simple and schematic way in the market, and lay out appropriate strategies for development.

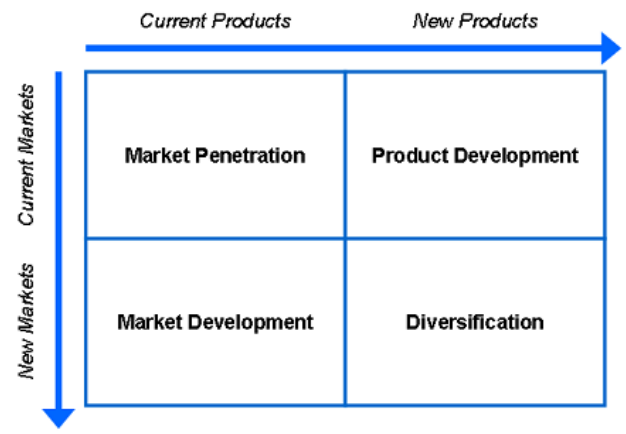

Fig -2: Ansoff Matrix [9]

Selection chance Matrix It is used to analyze potential product opportunities. Is constructed on several selection criteria, and weights are assigned according to degrees of importance. An opportunity is set as a reference and the other are ranked in relative terms "better than (+)", "worse than (-)" or "equals (0)". Establishing a final summation, indications of better opportunities [2] are obtained.

Product specifications sheets Is a document that describes market needs for a potential new product and its business opportunity. This tool is mainly used by management to decide on the initial investment of a new product and to guide the work of the PDP team [7].

\subsection{Project Planning Phase}

1. Define project stakeholders: Involves organizational project planning and the development of a team for implementation.

2. Define product scope: It consists in studying the project document and the previously defined product portfolio and establish basic guidelines of the product.

3. Define project scope: Involves defining the scope of the project taking into account scope of the product, work structure and restrictions imposed by the company and the project manager.

4. Adapting the Reference Model: Following the methodology proposed by Rozenfeld et al [1], involves sorting the project, identify the Reference Model -in this case, Penso [2]- and finally make necessary changes to suit to the particular organization.

5. Define activities and sequences: consists of identifying activities, relationships between them and analyzing the project network.

6. Prepare the schedule: It involves estimating the effort required for each activity, allocate resources, optimize the scheduling of activities and resources, and finally distribute the defined schedule.

7. Assess risks: It involves planning risk assessment of the project, a plan containing its identification and characterization, its qualitative and quantitative analysis, and finally actions to respond to any problems.

8. Prepare project budget: consists in forecasting expenditure related to the activities.

9. Analyze the economic viability of the project: involves defining target cost, verifying technical and commercial 
viability, define an estimated sales volume and perform preliminary economic assessment.

10. Defining performance indicators: involves selecting appropriate performance indicators to monitor the project.

- Planning procurement: Includes planning what should be purchased and at what time, prepare procurement requirements, identify potential suppliers and manage them.

11. Prepare the Project Plan: With all the information obtained, finally is made a project plan to develop the new product.

To carry forward the activities of this stage has been found in literature several tools mentioned below:

Function Deployment quality (or QFD, Quality Function Deployment). This method seeks to ensure quality throughout the PDP and was conceived to facilitate the project team to identify needs and desires of customers to translate them into technical specifications. The aim of this tool is focusing on meeting customer requirements, and establishing the importance of product attributes to transform them into technical requirements, based on a cascade of matrices [7]. It uses a graphical method where relationships between customer requirements and grid design characteristics are expressed. This matrix details the relationships between four dimensions: (i) product intrinsic quality, (ii) Technology required for its production, (iii) cost and (iv) Reliability. Thus, the first step is detecting needs, requirements and desires of customers (as required), and from this information defines quality characteristics of the final product, components, intermediate products and raw materials.

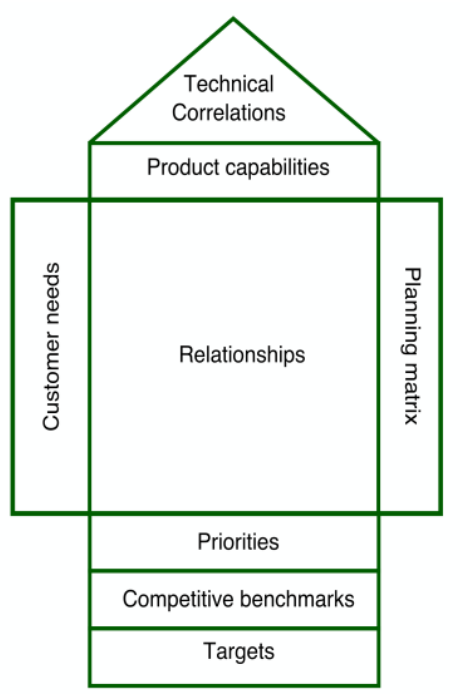

Fig -3: Quality Function Deployment [10]

Pricing Methods Within these tools, used for financial viability analysis of a new product, is the Subtraction Ceiling Price. It begins with the definition of a "ceiling" price to be set for the consumer, from which they are subtracting several costs: logistics, distribution, companu margin, product development costs, up to production cost [2].
Another method is known as Adding cost. Starts from the setting of component costs, and they are adding other costs: labor, indirect, manufacturing, development, profit margins and taxes [7].

Project specification sheet Is a document used to control development project. The list of project requirements covers both consumer requirements as those required for the manufacture, distribution, use, maintenance and disposal of the product, in addition to providing regulatory and legal requirements [3].

This tool tries to anticipate things that could cause failure of a commercial product, and serves to guide the project team during the next macrophase: Product Development [2].

\section{CONCLUSIONS}

According to the objective of this study, one of the first conclusions to mention is that was not found specific literature product development tools in the food industry, focused on Pre-Development Phase. Analyzed descriptions are related to tools in activities included in Pre Development Phase of many industries, or to Food Industries in general.

Furthermore, in the case of Food Industries tools, techniques are related mostly to facilitate activities in Development macrophase. Among them, there are sensory techniques, product development lifecycle map, Matrix attributes, morphological matrix, Sinetica, Mescrai, Audit Risk Products, Statistical optimization of processes, Taguchi Method, Triz, hazard Analysis critical points [2, 3, 7].

Furthermore, is observed in the analyzed literature related to PDP tools, the way they are known, systematized and classified depending on each author. The existence of many tools to do certain activities (eg, Consolidating information on market and technology) and some other gaps, especially for project planning phase, is also detected.

A number of tools that are considered appropriate to be applied at the stage of Pre-Development, according to the importance and purpose of the macrophase, have been presented in this paper. Subsequent research could focus on other tools to structure activities to be performed along each macrophase of product development process.

\section{ACKNOWLEDGEMENTS}

The authors acknowledge the financial contribution provided by the National Agency for Scientific and Technological Promotion, through Fund for Scientific and Technological Research (FONCYT) for the project "Design of a Management Model for Product Development in Small and Medium Food Production Enterprises" (PICT 2012 No. 1692 ) and also the Universidad Nacional del Litoral. 


\section{REFERENCES}

[1]. Rozenfeld, H., Forcellini, F.A., Amaral, D.C., Toledo, J.C., Silva, S.L., Alliprandini, D.H., Scalice, R.K., "Gestão de desenvolvimento de produtos: uma referência para a melhoria de processo", São Paulo, Ed. Saraiva, 2006.

[2]. Penso C.C., "Modelo de Referência para o Processo de Desenvolvimento de Produtos na Indústria de Alimentos" (Dissertação de Mestrado), Ed. UFSC, Florianópolis, 2003.

[3]. Lerma Kirchner, A, "Desarrollo de nuevos productos, una visión integral", Cuarta edición, Cengage Learning, Querétaro, México, 2010.

[4]. Roozemburg N. and Eekels J., "Product Design. Fundamentals and Methods", Ed. John Wily \& Sons, New York, 1995.

[5]. Rossetti G., Arcusin L., Giraudo F., Murer P, "Estudio Comparativo de Modelos de Gestión del Proceso de Desarrollo de Productos Alimenticios", Iberoamerican Journal of Project Management, vol.5, N ${ }^{\circ} .1,2014$, pp.11-22. [6]. Cóccaro, G.C. "Desarrollo de Nuevos Productos: Alimentos Funcionales y Novel Food. Alternativas para el diseño de alimentos y su marco legal". PROCAL (Programa de Gestión de Calidad y Diferenciación de los Alimentos), Ministerio de Agricultura, Ganadería y Pesca de la Nación, Argentina, 2010. Disponible en:

http://www.alimentosargentinos.gov.ar/contenido/procal/est udios/02/DesarrolloNuevosProductos.pdf

[7]. Val Jáuregui E. y Justel Lozano D, "Uso de herramientas durante la primera fase de desarrollo de productos", DYNA, Vol. 83, No 6, 2008, pp. 363-373.

[8]. Baxter, M. "Projeto de produto. Guia prática para design de novos productos", Ed. Blucher, São Paulo, 2008.

[9]. Vicente, M. y Ayala, J.C, "Principios Fundamentales para la Administración de Organizaciones", Pearson, Prentice Hall, Buenos Aires, 2008.

[10]. Hauser, J.R. y Clausing, D., "The house of quality", Harvard Business Review, May-June, 63-73, 1988

\section{BIOGRAPHIES}

Dr. Germán Rossetti is a chemical engineer, from UNL, Santa Fe, Argentina, and Ph.D from the same University. He is the director in the Dept of Industrial Engineering, and his research area includes product development management and project management.

M. Sc. Leticia Arcusin is pursuing Ph.D Degree in Administration from UNR University, Rosario, Argentina. She has completed her master degree in Strategic Business Management from UNaM, Misiones, Argentina. Her research area includes product development management.

BBA Melisa De Greef is pursuing Ph.D Degree in Administration from UNR University, Rosario, Argentina. She has completed his studies in Business Administration at UNL, Santa Fe, Argentina. Her research area includes product development management. 